\title{
Clinical characteristics of 194 cases of COVID-19 in Huanggang and Taian, China
}

\author{
Hong Zhang ${ }^{1} \cdot$ Wenli Shang ${ }^{2} \cdot$ Qinghua Liu $^{3} \cdot$ Xuejing Zhang $^{4} \cdot$ Maochuan Zheng $^{2} \cdot$ Maokui Yue $^{2}$
}

Received: 10 March 2020 / Accepted: 4 May 2020 / Published online: 10 May 2020

c) Springer-Verlag GmbH Germany, part of Springer Nature 2020

\begin{abstract}
Purpose We aimed to report the clinical characteristics of 194 cases coronavirus disease-19 (COVID-19) in Huanggang, Hubei and Taian, Shandong.

Methods We retrospectively investigated the clinical, laboratory characteristics and CT imaging of confirmed cases of COVID-19 from January 22 to February 28, 2020 in Huanggang Central Hospital and The Second Affiliated Hospital of Shandong First Medical University. Real time PCR was used to detect the new coronavirus in respiratory samples. Immunohistochemical staining was used to detect the expressions of ACE2 in tissues.

Results Among the 194 patients infected with COVID-19, 108 patients were male, with a median age of 48.3 years. The average preclinical period was 7.44 day. Except for 37 severe or critically ill patients, the rest of the 157 patients exhibited mild or moderate symptoms. 190 (97.94\%) patients were confirmed during the three times nucleic acid test. The main clinical symptom of the patients were fever, sore throat and cough, which accounted for 146 cases (75.26\%), 98 (50.52\%) and 86 cases $(44.33 \%)$, respectively. 30 patients (15.46\%) showed liver dysfunction. Imaging examination showed that 141 patients (72.68\%) showed abnormal density shadow, while 53 cases $(27.32 \%)$ had no obvious abnormality in the parenchyma of both lungs. Up to now, 109 cases have been discharged from the hospital, and 9 patients died. The ACE2 expression levels were up-regulated in patients of severe type and critically ill type.

Conclusion Clinical symptoms, laboratory tests and CT imaging should be combined for comprehensive analysis to diagnose COVID-19. ACE2 may be the receptor of COVID-19.
\end{abstract}

Keywords Coronavirus disease-19 (COVID-19) - Clinical characteristics · Novel coronavirus pneumonia $\cdot$ Huanggang · Taian $\cdot$ ACE2

Hong Zhang and Wenli Shang contributed equally to this work.

Electronic supplementary material The online version of this article (https://doi.org/10.1007/s15010-020-01440-5) contains supplementary material, which is available to authorized users.

Maokui Yue

maokuiyue@126.com

1 Department of Hematopathology, The Second Affiliated Hospital of Shandong First Medical University, Taian 271000, China

2 Department of Critical Care Medicine, The Second Affiliated Hospital of Shandong First Medical University, No. 706 Taishan Road, Taian 271000, China

3 Department of Clinical Laboratory, The Second Affiliated Hospital of Shandong First Medical University, Taian 271000, China

4 Taian Daiyue Maternal and Child Care Service Centre, Taian 271000, China

\section{Introduction}

In December 2019, clusters of novel pneumonia caused by COVID-19, the 2019 novel coronavirus, broke out in Wuhan, Hubei, China. This novel coronavirus has been recently identified as a type of beta coronavirus, with a diameter of 60-140 nm, which enveloped virions that appear as oval or round and polymorphous following the strong infectivity and general susceptibility to people of all ages and across the globe [1,2]. Since December 2019, a large number of patients infected with COVID-19 have been reported around the world [3-6].

Up to March 10, 2020, 80,928 cases were confirmed in China, including 67,760 cases in Hubei Province, with49,965 cases in Wuhan City. Gratifyingly, the outbreak of COVID-19 is well controlled in China now, with wellhealed patients, 60,195. Unfortunately, 33,830 cases have 
been confirmed besides China, including 7513 cases in South Korea, 9172 cases in Italy and 8042 cases in Iran. Although control measures have been applied to prevent further spread in China, including isolation of people suspected to have the disease, the need for better diagnosis and treatment of patients with pneumonia is no longer limited to China now, especially with the increasing numbers of infected patients worldwide, especially in South Korea, Italy and Iran. So far, several studies have described the epidemiological and clinical characteristics of patients infected with COVID-19 [7-10]; however, the clinical characteristics of patients remain indistinct due to the rarity of reported samples.

In this study, the clinical characteristics and CT imaging features of 194 patients diagnosed with COVID-19 in Huanggang Central Hospital and The Second Affiliated Hospital of Shandong First Medical University were discussed. We believe our findings will give further details of the epidemic situation and clinical characteristics of this novel coronavirus.

\section{Methodology}

\section{Patients}

194 patients were consecutively enrolled from January 22 to February 28, 2020 in Huanggang Central Hospital (178 cases) and The Second Affiliated Hospital of Shandong First Medical University (16 cases). Written informed consent was obtained. The study was approved by the Ethics Committee of The Second Affiliated Hospital of Shandong First Medical University (NO. 2020TMU001\#). All the patients were hospitalized and had laboratory-confirmed COVID-19 infection. Real-time reverse-transcription polymerase chain reaction (RT-PCR) assay was used to detect COVID-19 according to the manufacturer's protocol provided by The Beijing Genomics Institute (BGI, Beijing, China). We collected all the data including demographic data, clinical data, laboratory parameters and chest CT from patients' medical records and attending doctors.

\section{Laboratory confirmation}

Epidemiological data, clinical laboratory data and radiological characteristics and treatment and outcomes data were obtained with standardized data collection forms from electronic medical records and checked by both on-site and offsite doctors. The real-time reverse-transcriptase polymerase chain reaction (RT-PCR) test was performed to detect coronavirus according to the manufacturer's instructions.

\section{Disease stage}

The disease stage was classified according to the Diagnosis and Treatment Scheme of COVID-19 (The Seventh) provided by the National Health Commission of the People's Republic of China (https://www.nhc.gov.cn/yzygj/s7653 p/202003/46c9294a7dfe4cef80dc7f5912eb1989.shtml).

Mild: mild clinical symptoms and no pneumonia was seen through imageological examination. Moderate: fever, respiratory symptom and pneumonia were seen through imageological examination. Severe: shortness of breath, $\mathrm{RR} \geq 30$ times/min; oxygen saturation $\leq 93 \% ; \mathrm{PaO}_{2} /$ $\mathrm{FiO}_{2} \leq 300 \mathrm{mmHg}$.

\section{Statistical analysis}

Statistical analyses were performed with SPSS (v.19.0; SPSS Inc., Chicago, IL, USA). Categorical data were presented as number (\%) and tested with Chi square test or Fisher's exact test. Continuous data were presented as mean $\pm \mathrm{SD}$ (standard deviation) and tested with paired $t$ test.

\section{Results}

\section{The clinical characteristics of patients infected with COVID-19}

In this study, 194 cases infected with COVID-19 in Huanggang Central Hospital and The Second Affiliated Hospital of Shandong First Medical University were studied. Among them, the average preclinical period was 7.44 days. The longest preclinical period was 18 days and the shortest period was 0.08 day. $96.9 \%$ patients were imported infections (with a history of epidemic in Wuhan) and 3.1\% patients had contact with the seafood market in Wuhan, China. 108 patients (55.67\%) were male. 106 patients $(54.64 \%)$ were aged 31-50 years, 41 patients $(21.13 \%)$ were aged $51-70$ years, 17 patients $(8.76 \%)$ were aged $18-30$ years, 8 patients $(4.13 \%)$ were under 18 years, and 22 patients $(11.34 \%)$ were over 71 years. In terms of clinical classification, 116 (59.79\%) patients were mild type, 41 (21.13\%) patients were moderate type, 25 (12.89\%) patients were severe type and 12 patients $(6.19 \%)$ were critically ill type. During the diagnostic procedure by nucleic acid tests, we found that 112 patients $(57.73 \%)$ got a positive result in the first test, 45 patients $(23.30 \%)$ got a positive result in the second test, 33 patients (17.01\%) got a positive result in the third test, and 3 patients $(1.55 \%)$ got a positive result in the fourth test. Surprisingly, another patient $(0.51 \%)$ remained negative until the fifth test (Table 1). The most common symptoms were 
Table 1 Demographics, baseline and clinical characteristics of patients infected with COVID-19

\begin{tabular}{|c|c|}
\hline Variables & Patients $(n=194)$ \\
\hline Age (years) & $48.3(33-56)$ \\
\hline$<18$ & $8(4.13 \%)$ \\
\hline $18-30$ & $17(8.76 \%)$ \\
\hline $31-50$ & $106(54.64 \%)$ \\
\hline $51-70$ & $41(21.13 \%)$ \\
\hline$>71$ & $22(11.34 \%)$ \\
\hline \multicolumn{2}{|l|}{ Sex } \\
\hline Female & $86(44.33 \%)$ \\
\hline Male & $108(55.67 \%)$ \\
\hline \multicolumn{2}{|l|}{ Clinical classification } \\
\hline Mild type & $116(59.79 \%)$ \\
\hline Moderate type & $41(21.13 \%)$ \\
\hline Severe type & $25(12.89 \%)$ \\
\hline Critically ill type & $12(6.19 \%)$ \\
\hline \multicolumn{2}{|l|}{ Types of infection } \\
\hline Huanan seafood wholesale market exposure & $6(3.1 \%)$ \\
\hline Imported infections & $188(96.9 \%)$ \\
\hline \multicolumn{2}{|l|}{ Number of nucleic acid tests } \\
\hline The first time & $112(57.73 \%)$ \\
\hline The second time & $45(23.20 \%)$ \\
\hline The third time & $33(17.01 \%)$ \\
\hline The fourth time & $3(1.55 \%)$ \\
\hline The fifth time & $1(0.51 \%)$ \\
\hline \multicolumn{2}{|l|}{ Signs and symptoms at admission } \\
\hline Fever & $146(75.26 \%)$ \\
\hline Cough & $86(44.33 \%)$ \\
\hline Shortness of breath & $71(36.60 \%)$ \\
\hline Muscle ache & $44(22.68 \%)$ \\
\hline Headache & $33(17.01 \%)$ \\
\hline Sore throat & $98(50.52 \%)$ \\
\hline Chest pain & $47(24.22 \%)$ \\
\hline Diarrhea & $36(18.56 \%)$ \\
\hline More than one sign or symptom & $169(87.11 \%)$ \\
\hline \multicolumn{2}{|l|}{ Chest X-ray and CT findings } \\
\hline Bilateral pneumonia & $101(52.06 \%)$ \\
\hline Unilateral pneumonia & $40(20.62 \%)$ \\
\hline No abnormal density shadow & $53(27.32 \%)$ \\
\hline \multicolumn{2}{|l|}{ Clinical outcome } \\
\hline Discharged & $109(56.19 \%)$ \\
\hline Remained in hospital & $76(39.17 \%)$ \\
\hline Died & $9(4.64 \%)$ \\
\hline
\end{tabular}

$n / N(\%)$, where $N$ is the total number of patients with available data.

fever, sore throat and cough, which accounted for 146 cases (75.26\%), 98 (50.52\%) and 86 cases (44.33\%), respectively. 71 cases $(36.60 \%)$ had shortness of breath. In addition, 44
(22.68\%) patients had muscle ache, 33 patients $(17.10 \%)$ had headache, and 36 patients (18.56\%) had diarrhea symptoms. Unfortunately, nine patients (4.64\%) died.

\section{Laboratory findings of patients infected with COVID-19}

The white blood cell (WBC) count of 75 patients (38.66\%) was lower than the normal range $\left(3.5 \times 10^{9} / \mathrm{L}\right)$ and of 29 patients $(14.95 \%)$ higher than the normal range $\left(9.5 \times 10^{9} / \mathrm{L}\right)$. 94 patients $(48.45 \%)$ had lymphocytopenia (the lymphocyte count was less than $\left.1.0 \times 10^{9} / \mathrm{L}\right) .51$ patients $(26.29 \%)$ had platelets lower than the normal range $\left(100 \times 10^{9} / \mathrm{L}\right)$, and no patients had platelets higher than the normal range $\left(300 \times 10^{9} / \mathrm{L}\right)$.

There were 119 patients $(61.34 \%)$ with high C-reactive protein (CRP). The level of D-dimer was increased in 27 patients (13.92\%). 19 patients $(9.80 \%)$ had lower albumin level than the normal range $(35 \mathrm{~g} / \mathrm{L})$. In terms of liver function, 30 patients $(15.46 \%)$ showed alanine transaminase (ALT) and aspartate aminotransferase (AST) above the normal range. 65 patients $(32.51 \%)$ had abnormal myocardial enzyme spectrum, indicating the increase of creatine kinase (CK). The level of creatinine increased in 24 patients (12.37\%). The level of lactate dehydrogenase (LDH) increased in 83 patients (42.78\%) (Table 2).

\section{Imaging features of patients infected with COVID-19}

Among the 194 patients, 141 (72.68\%) showed abnormal chest CT images, consisting of 101 cases (52.06\%) of bilateral pneumonia and 40 cases $(20.62 \%)$ of unilateral pneumonia (Table 1). Some lesions might have a mixed pattern of consolidation in the center and ground glass opacity in the periphery (Fig. 1). In severe or critically severe patients, multiple patches or an integrated larger patch of ground glass opacity, consolidation or mixed consolidation and ground glass opacity might present in bilateral lungs (Fig. 2).

\section{Treatment for patients infected with COVID-19}

All patients were treated empirically with the antibiotic, mainly ribavirin or lopinavir or resochin and IFN- $\alpha$. The duration of antibiotic treatment was less than 10 days. Five patients used the invasive ventilator.

\section{The prognosis of patients infected with COVID-19}

Up to March 3, 109 patients (56.19\%) were discharged from the hospital and 9 (4.64\%) patients died. 
Table 2 Laboratory findings of imported patients infected with COVID-19

\begin{tabular}{|c|c|}
\hline Laboratory results & Patients $(n=194)$ \\
\hline White blood cell count, $\times 10^{9} / \mathrm{L}$ & $5.6(3.6-11.1)$ \\
\hline$<4$ & $75(38.66 \%)$ \\
\hline $4-10$ & $90(46.39 \%)$ \\
\hline$>10$ & $29(14.95 \%)$ \\
\hline Lymphocyte count, $\times 10^{9} / \mathrm{L}$ & $1.2(0.7-2.6)$ \\
\hline$<1$ & $94(48.45 \%)$ \\
\hline $1-3.3$ & $61(31.44 \%)$ \\
\hline$>3.3$ & $39(20.11 \%)$ \\
\hline Platelet count, $\times 10^{9} / \mathrm{L}$ & $168(117-239)$ \\
\hline$<100$ & $51(26.29 \%)$ \\
\hline $100-300$ & $143(73.71 \%)$ \\
\hline$>300$ & $0(0.0 \%)$ \\
\hline C-reactive protein, $\mathrm{mg} / \mathrm{L}$ & $15.8(8.9-21.2)$ \\
\hline$\leq 10$ & $75(38.66 \%)$ \\
\hline$>10$ & $119(61.34 \%)$ \\
\hline D-dimers, mg/L & $0.3(0.1-0.4)$ \\
\hline$\leq 0.5$ & $167(86.08 \%)$ \\
\hline$>0.5$ & $27(13.92 \%)$ \\
\hline Albumin, $\mathrm{g} / \mathrm{L}$ & $43.5(36.1-48.3)$ \\
\hline$\leq 35$ & $19(9.80 \%)$ \\
\hline$>35$ & $175(91.20 \%)$ \\
\hline Alanine aminotransferase, U/L & $25.6(22.1-37.7)$ \\
\hline$\leq 40$ & $164(84.54 \%)$ \\
\hline$>40$ & $30(15.46 \%)$ \\
\hline Aspartate aminotransferase, U/L & $30.1(15.1-36.9)$ \\
\hline$\leq 40$ & $164(84.54 \%)$ \\
\hline$>40$ & $30(15.46 \%)$ \\
\hline Creatinine, $\mu \mathrm{mol} / \mathrm{L}$ & $79.0(55.0-99.0)$ \\
\hline$\leq 115$ & $170(87.63 \%)$ \\
\hline$>115$ & $24(12.37 \%)$ \\
\hline Creatine kinase, U/L & $138.0(62.2-218.6)$ \\
\hline$\leq 200$ & $129(66.49 \%)$ \\
\hline$>200$ & $65(32.51 \%)$ \\
\hline Lactate dehydrogenase, U/L & $201.0(127.0-316.0)$ \\
\hline$\leq 250$ & $111(57.22 \%)$ \\
\hline$>250$ & $83(42.78 \%)$ \\
\hline
\end{tabular}

Data are median (IQR), $n / N(\%)$, where $N$ is the total number of patients with available data

The average length of stay of discharged patients was 10.2 days. Fitness for discharge was based on temperature returning to normal for more than 3 days, respiratory pathogenic nucleic acid test negative for two consecutive times and the improvement of chest radiographic evidence.

\section{The expression of ACE2 in patients with COVID-19}

We used IHC to detect the ACE2 protein levels of two patients who died of COVID-19. The results showed that the ACE2 protein levels were up-regulated in severe type and critically ill type compared with the adjacent normal tissue of lung, especially in critically ill type (Fig. 3a-c). We detected the expression levels of ACE2 in the serum of COVID-19 patients by ELISA assay and found that the ACE2 levels were up-regulated in the serum of patients (Fig. 3d). In addition, we analyzed the expression of ACE2 after being infected with SARS-CoV through the data of GSE17400. The results showed that $24 \mathrm{~h}$ after SARS-CoV infection, the expression of ACE2 dramatically increased compared to the expression at $12 \mathrm{~h}$. After $48 \mathrm{~h}$, the expression of ACE2 remained at a high level (Fig. 3e).

\section{Discussion}

Coronaviruses infect many species of animals including humans, causing acute and chronic diseases [11]. Coronaviruses are a family of viruses within the Nidovirus superfamily, divided into three groups due to antigenic reactivity, including alpha, beta and gamma coronaviruses [12].

Recently, COVID-19 infection has occurred and spread in the mainland of China, South Korea, Italy and Iran, and so on. This novel COVID-19 has been recently identified as a type of beta coronavirus, with a diameter of $60-140 \mathrm{~nm}$ [2]. Researchers have revealed that the COVID-19 virus is similar to severe acute respiratory syndrome coronavirus (SARS-CoV). The closest genetic similarity was found in a coronavirus isolated from bats $[13,14]$. SARS is a novel infectious disorder that was first diagnosed in November 2002 in China and subsequently spread worldwide $[15,16]$. SARS was documented in over 8000 persons with 778 deaths before the outbreak was extinguished [17]. Unfortunately, until now, COVID-19 has been documented in over 94,084 persons with 3218 deaths.

In 2003, patients with SARS were via airborne droplets and through fomites [17]. At present, patients with COVID-19 are the main source of infection through respiratory droplets and contact $[18,19]$. Clinically, patients with SARS had a triphasic pattern of disease, including fever, a nonproductive cough, sore throat, and myalgia [20]. In the present study, patients with COVID-19 had 

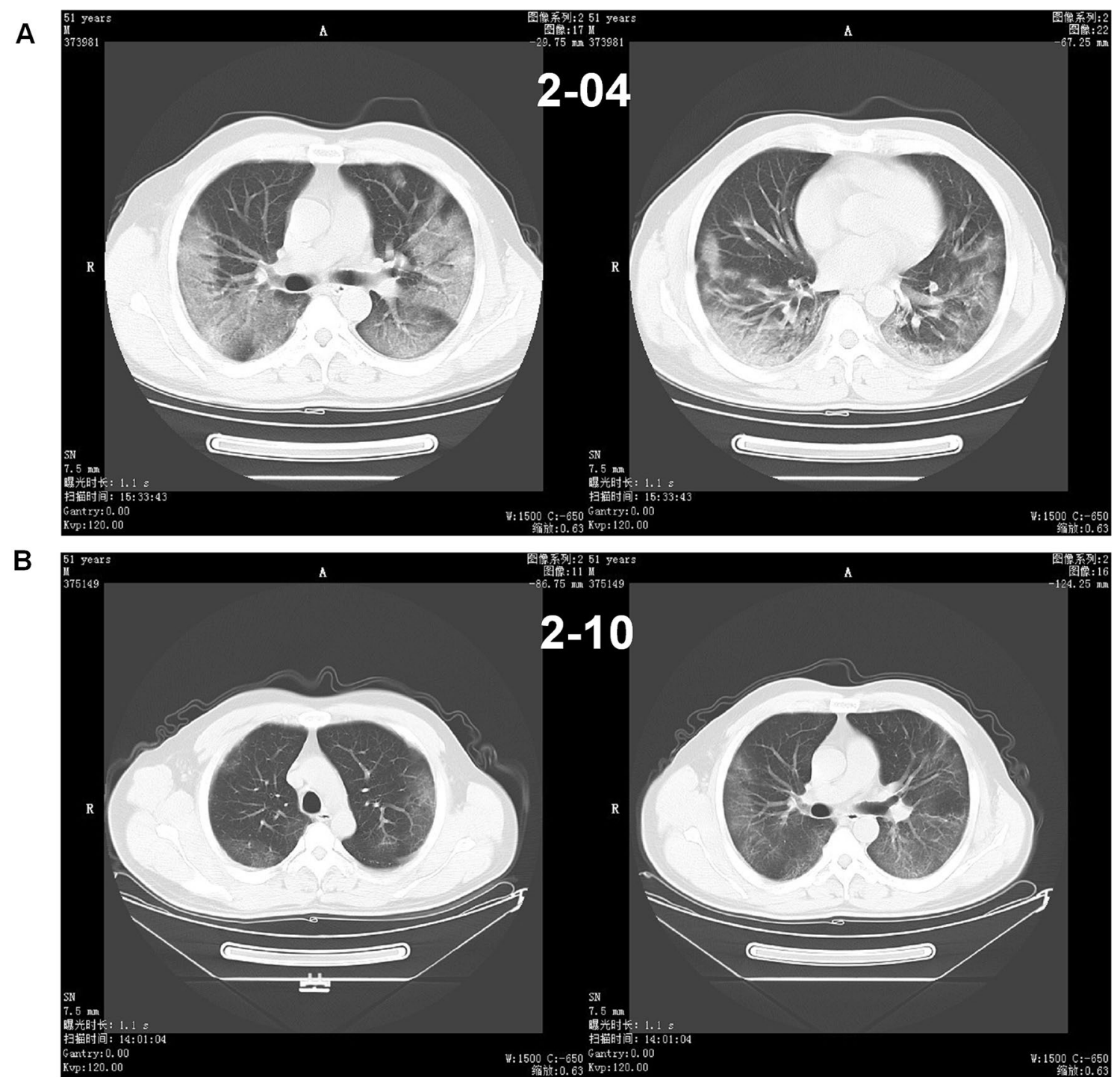

Fig. 1 Chest CT of a male patient, 51 years old. a He underwent a chest CT examination on February 4, which showed a piece of peripheral ground glass opacity with consolidation in the lower lobes of the two lungs. b 6 days after treatment, the CT images of February 10 showed a decrease in density of the pulmonary lesions with fibrosis formation fever $(75.26 \%)$, cough $(44.33 \%)$, sore throat $(50.52 \%)$, and myalgia (22.68\%).

Kuba et al. reported that the expression levels of ACE2 on the surface of lung cells were downregulated after infection with SARS-CoV [21]. However, we found that the ACE2 protein levels were up-regulated in severe type and critically ill type compared with the adjacent normal tissue of lung, especially in critically ill type. This result demonstrates that ACE2 may be the receptor of COVID-19. Recently, Hoffmann et al. reported that
SARS-CoV-2 cell entry depends on ACE2 and TMPRSS2 and is blocked by a clinically proven protease inhibitor [22]. They also reveal the important commonalities between SARS-CoV-2 and SARS-CoV infection and identify a potential target for antiviral intervention, because there is no specific drug for the treatment of patients with COVID-19 now.

In terms of laboratory tests, $38.66 \%$ patients had a decreased number of WBC and nearly half (48.45\%) of the patients had a decreased number of lymphocytes. The CRP level was increased in 119 patients (61.34\%). In some 


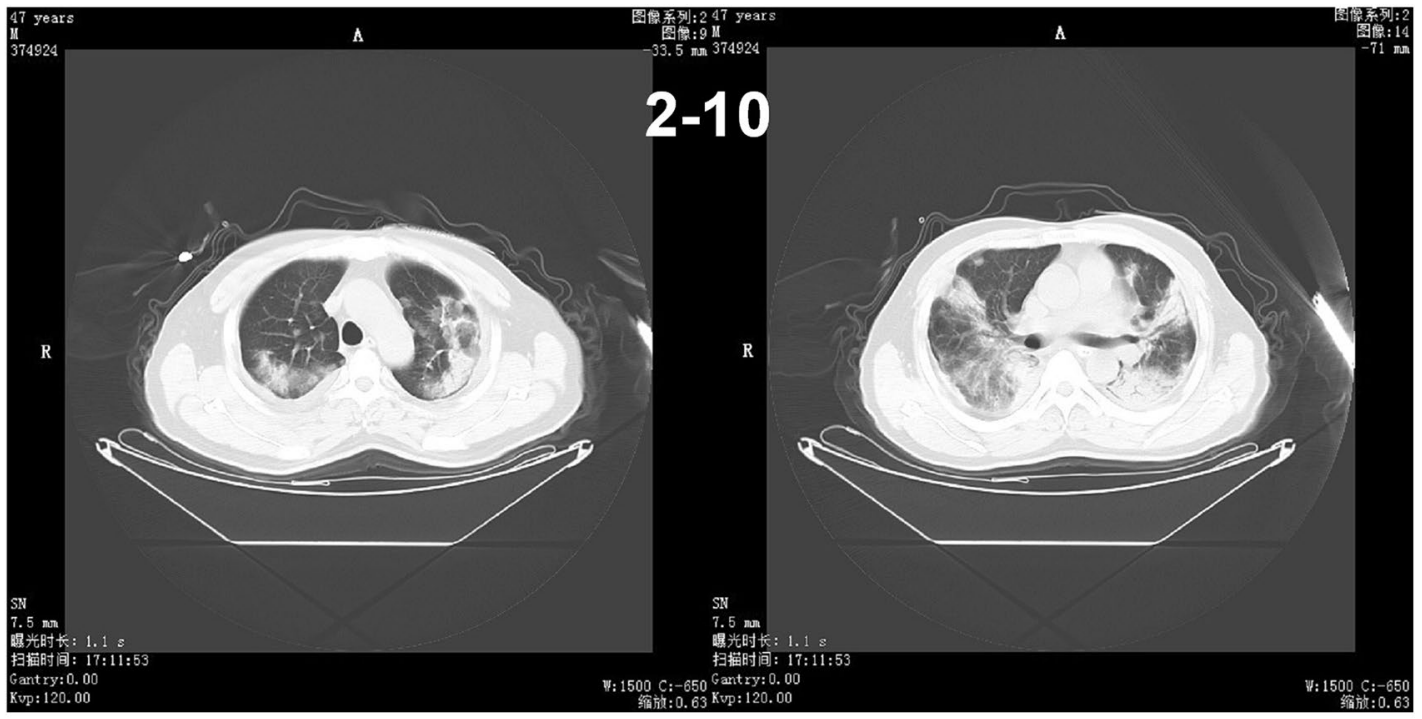

B

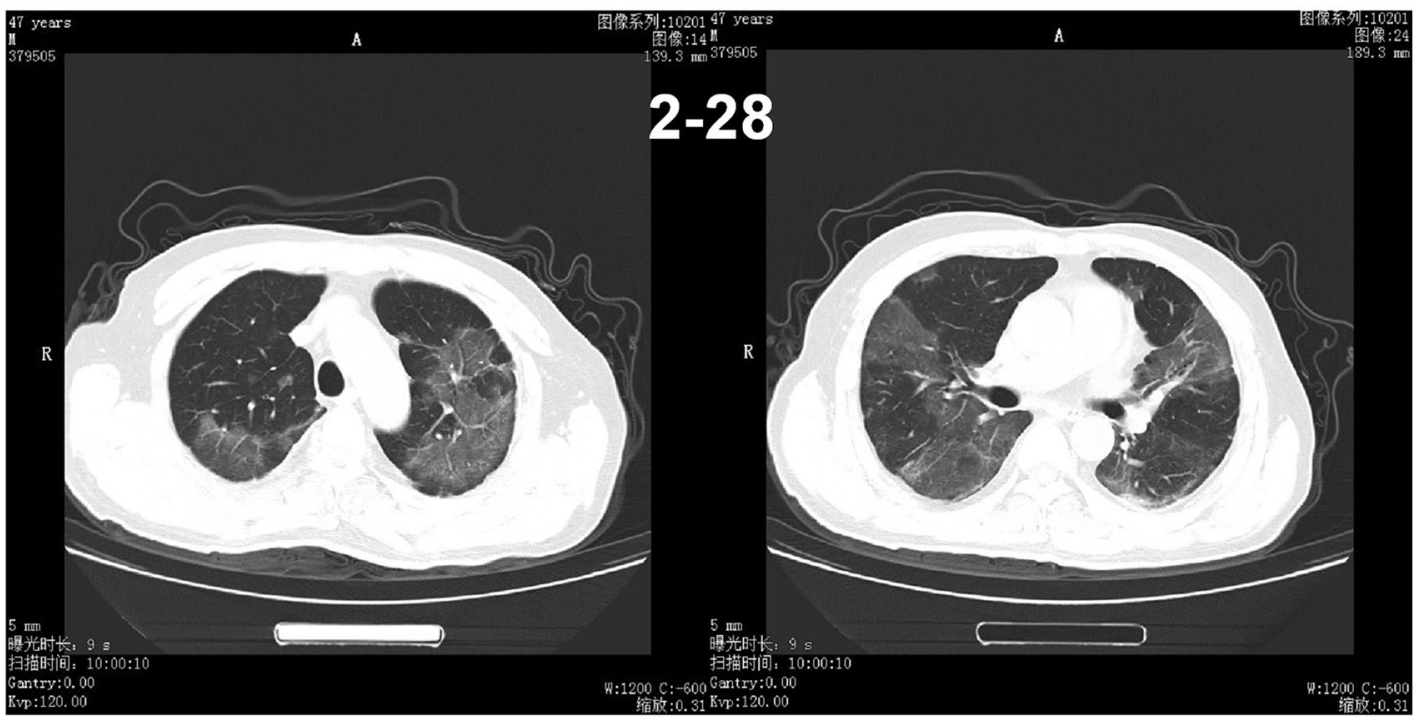

Fig. 2 Chest CT of a male patient, 47 years old. a He underwent a chest CT examination on February 10, which showed multiple lesions of peripheral ground glass opacity with consolidation and fibrosis in the two lungs. b 18 days after treatment, the CT images of February 10 showed a decrease in density of the pulmonary lesions with fibrosis format patients, alanine aminotransferase, aspartate aminotransferase, creatinine, creatine kinase and lactate dehydrogenase may increase. In addition, all cases were confirmed by nucleic acid test. $112(57.73 \%)$ patients got positive results during the three tests. Furthermore, the CT images of $72.68 \%$ patients were abnormal. Due to the complexity and non-determinacy, clinical symptoms, laboratory tests and CT should be combined for comprehensive analysis to diagnose COVID-19.

In summary, COVID-19 is dangerous and severe, the mechanism of occurrence and development of COVID-19 is unclear at this time, and hence in-depth study is still needed for patients with COVID-19. 
Fig. 3 The expression levels of ACE2 in patients with COVID119. a IHC showed the expression levels of ACE2 in the adjacent tissues of lung. b IHC showed the expression levels of ACE2 in the severe type. $\mathbf{c}$ IHC showed the expression levels of ACE2 in the critically ill type. d ELISA assay was used to detect the ACE2 expression in 20 normal serum and 20 COVID19 patient serum. e The data of GSE17400 showed the expression of ACE2 after SARS-CoV infection at 12,24 and $48 \mathrm{~h}$
A

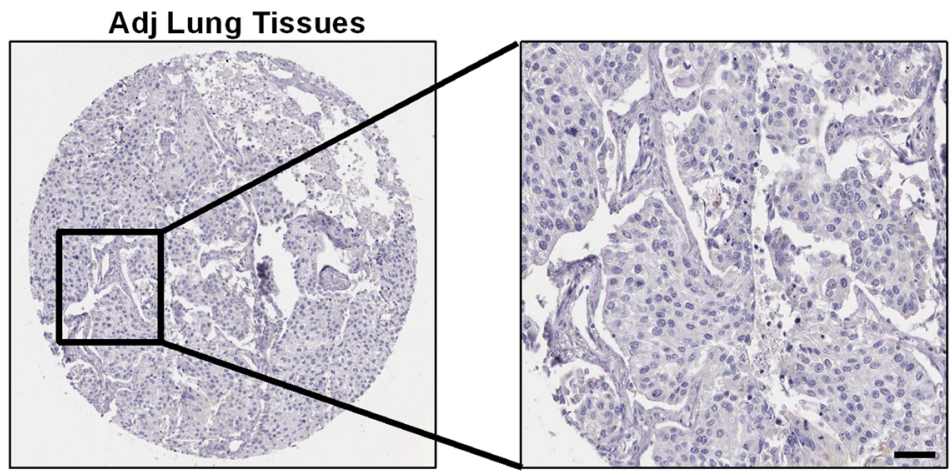

Severe type of COVID-19

B

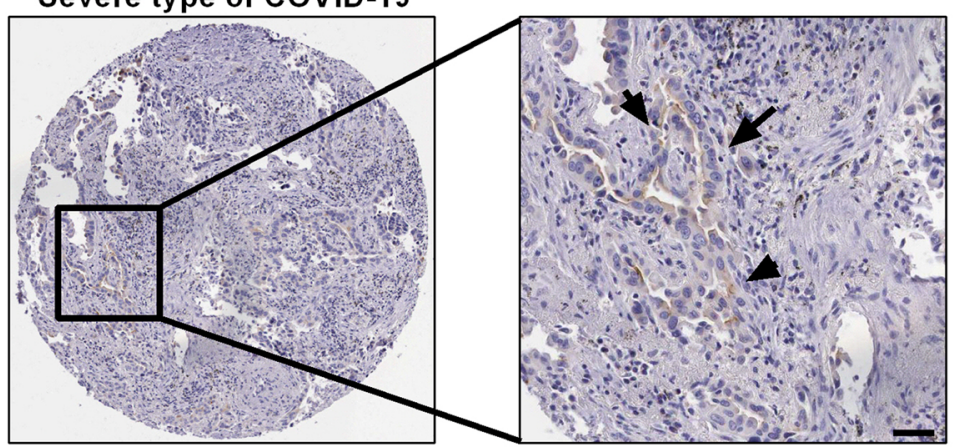

C

Critically ill type of COVID-19

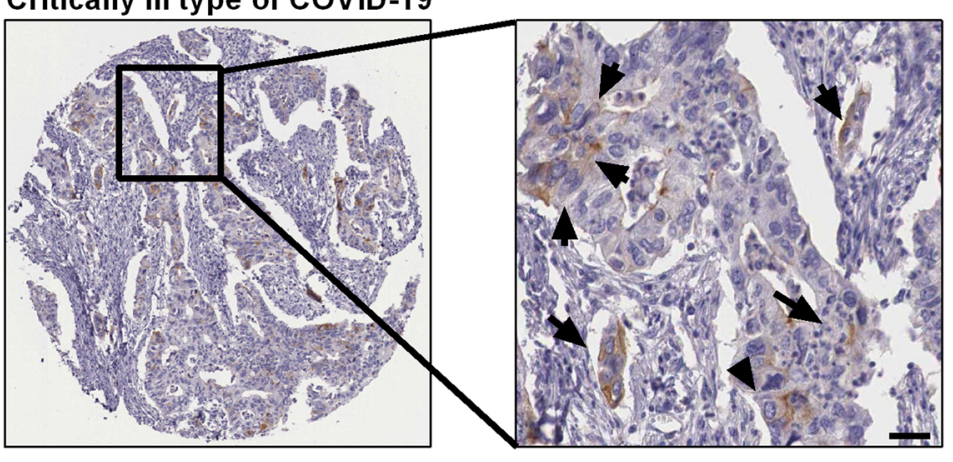

IHC for ACE2

D

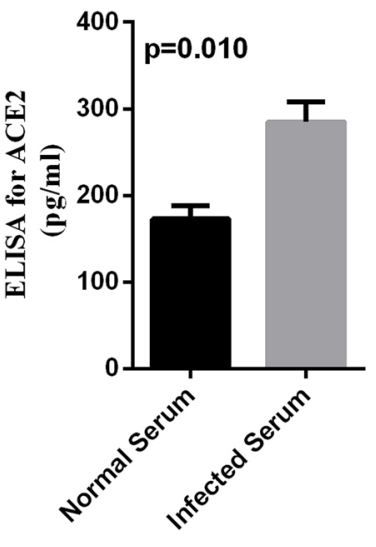

E

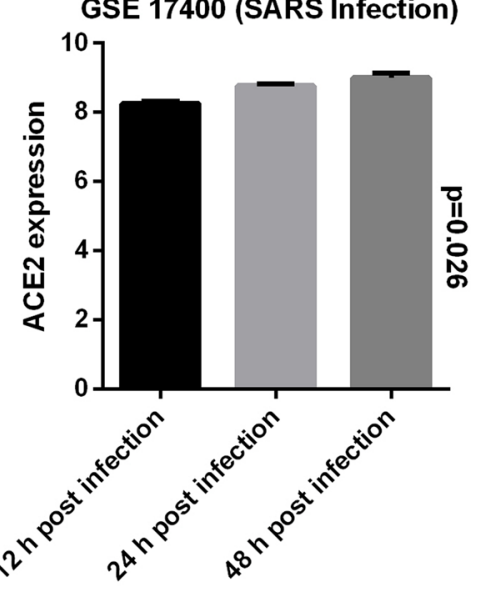


Funding This study was supported by The Project of COVID-19 of Taian, Shandong Province.

\section{Compliance with ethical standards}

Conflict of interest All authors declared that there were no competing interests.

Ethical approval The Second Affiliated Hospital of Shandong First Medical University approved the study (COVID-19-2020, No. 2020TMU001\#) and this approval was confirmed by the First Medical University Of Shandong. This study was performed in accordance with the Helsinki Declaration of 1964 and its later amendments.

Informed consent Yes, informed consent was obtained.

\section{Reference}

1. Zhao S, Lin Q, Ran J, et al. Preliminary estimation of the basic reproduction number of novel coronavirus (2019-nCoV) in China, from 2019 to 2020: a data-driven analysis in the early phase of the outbreak. Int J Infect Dis. 2020;92:214-7. https:// doi.org/10.1016/j.ijid.2020.01.050.

2. Zhou P, Yang XL, Wang XG, et al. A pneumonia outbreak associated with a new coronavirus of probable bat origin. Nature. 2020;579:270-3. https://doi.org/10.1038/s41586-020-2012-7.

3. Lillie PJ, Samson A, Li A, et al. Novel coronavirus disease (Covid-19): the first two patients in the UK with person to person transmission. J Infect. 2020. https://doi.org/10.1016/j. jinf.2020.02.020.

4. Lim J, Jeon S, Shin HY, et al. Case of the index patient who caused tertiary transmission of COVID-19 infection in Korea: the application of lopinavir/ritonavir for the treatment of COVID-19 infected pneumonia monitored by quantitative RT-PCR. J Korean Med Sci. 2020;35:e79. https://doi.org/10.3346/jkms.2020.35.e79.

5. Nishiura $\mathrm{H}$. Backcalculating the incidence of infection with COVID-19 on the diamond princess. J Clin Med. 2020. https:// doi.org/10.3390/jcm9030657.

6. Zhang Y, Xu J, Li H, Cao B. A novel coronavirus (COVID-19) outbreak: A call for action. Chest. 2020. https://doi.org/10.1016/j. chest.2020.02.014.

7. Tian S, Hu N, Lou J, et al. Characteristics of COVID-19 infection in Beijing. J Infect. 2020. https://doi.org/10.1016/j. jinf.2020.02.018.

8. Wu J, Liu J, Zhao X, et al. Clinical characteristics of imported cases of COVID-19 in Jiangsu province: a multicenter descriptive study. Clin Infect Dis. 2020. https://doi.org/10.1093/cid/ciaa199.
9. Xu YH, Dong JH, An WM, et al. Clinical and computed tomographic imaging features of novel coronavirus pneumonia caused by SARS-CoV-2. J Infect. 2020. https://doi.org/10.1016/j. jinf.2020.02.017.

10. Yang W, Cao Q, Qin L, et al. Clinical characteristics and imaging manifestations of the 2019 novel coronavirus disease (COVID19): a multi-center study in Wenzhou city, Zhejiang, China. J Infect. 2020. https://doi.org/10.1016/j.jinf.2020.02.016.

11. Weiss SR, Leibowitz JL. Coronavirus pathogenesis. Adv Virus Res. 2011;81:85-164. https://doi.org/10.1016/B978-0-12-38588 5-6.00009-2.

12. Brian DA, Baric RS. Coronavirus genome structure and replication. In: Enjuanes L, editor. Coronavirus replication and reverse genetics. Current topics in microbiology and immunology, vol 287. Berlin, Heidelberg: Springer; 2005.

13. Heymann DL, Shindo N. COVID-19: what is next for public health? Lancet. 2020;395:542-5. https://doi.org/10.1016/S0140 $-6736(20) 30374-3$.

14. Lu R, Zhao X, Li J, et al. Genomic characterisation and epidemiology of 2019 novel coronavirus: implications for virus origins and receptor binding. Lancet. 2020;395:565-74. https://doi. org/10.1016/S0140-6736(20)30251-8.

15. Ding $Y$, Wang $H$, Shen $H$, et al. The clinical pathology of severe acute respiratory syndrome (SARS): a report from China. J Pathol. 2003;200:282-9.

16. Lee $\mathrm{N}$, Hui D, Wu A, et al. A major outbreak of severe acute respiratory syndrome in Hong Kong. $\mathrm{N}$ Engl $\mathrm{J}$ Med. 2003;348:1986-94.

17. Parashar UD, Anderson LJ. Severe acute respiratory syndrome: review and lessons of the 2003 outbreak. Int J Epidemiol. 2004;33:628-34.

18. Chen ZM, Fu JF, Shu Q, et al. Diagnosis and treatment recommendations for pediatric respiratory infection caused by the 2019 novel coronavirus. World J Pediatr. 2020. https://doi.org/10.1007/ s12519-020-00345-5.

19. Yang F, Liu N, Wu JY, Hu LL, Su GS, Zheng NS. Pulmonary rehabilitation guidelines in the principle of $4 \mathrm{~S}$ for patients infected with 2019 novel coronavirus (2019-nCoV). Zhonghua Jie He He Hu Xi Za Zhi. 2020;43:E004. https://doi.org/10.3760/cma.j.i ssn.1001-0939.2020.0004.

20. Peiris JS, Chu CM, Cheng VC, et al. Clinical progression and viral load in a community outbreak of coronavirus-associated SARS pneumonia: a prospective study. Lancet. 2003;361:1767-72.

21. Kuba K, Imai Y, Rao S, et al. A crucial role of angiotensin converting enzyme 2 (ACE2) in SARS coronavirus-induced lung injury. Nat Med. 2005;11:875-9. https://doi.org/10.1038/nm1267.

22. Hoffmann M, Kleine-Weber H, Schroeder S, et al. SARS-CoV-2 cell entry depends on ACE2 and TMPRSS2 and is blocked by a clinically proven protease inhibitor. Cell. 2020. https://doi. org/10.1016/j.cell.2020.02.052. 